\title{
On the Disturbance of the Atmospheric Potential Gradient caused by the Eruption-smoke of the Volcano Aso
}

by

\author{
H. Hatakeyama and K. Uchikawa \\ Meteorological Research Institute, \\ and Honjo Branch Station of the Aerological Observatory \\ (Received Jan. 4, 1951)
}

\begin{abstract}
The disturbance of the atmospheric potential gradient, caused by the eruption-smoke of the Volcano Aso, was observed in the neighbourhood of the crater. It was found that the disturbance was positive when the volcanic ashes were falling. The negative disturbance was often observed in short durations when the tip of the smoke reached the zenith of the observing spot. The electrification of ashes by the mutual collision was investigated in the laboratory and it was found that the larger particle got the positive electricity and smaller particle the negative.
\end{abstract}

\section{Introduction}

The disturbance of the atmospheric potential gradient caused by the smokecloud ever observed in Japan was always negative in the cases of Volcanos Asamayama, (1) Sakurajima(3) and Yake-yama ${ }^{(3)}$. Volcano Aso in Kumamoto Prefecture in Kyushu recovered its activity from December, 1949. The authors of the present paper had interests in sign and type of the disturbance of potential gradient and observed them with the portable electrometer ${ }^{(4)}$ very near the crater of Aso in the middle of February, 1950.

The topographical map of the crater of Aso and its neighbourhood is shown in Fig. 1. Observing spots are shown with marks $A$ and B in Fig. 1. The crater No. 1 was active in these days and the black smoke which contained the large quantity of ashes erupted with many pieces of lava at intervals of several minutes. Almost all the pieces of lava dropped into the crater again but the smoke was

(1) H. Hatakeyaina: Journ. Met. Soc. Japan. Vol. 21, p. 49, 420,426, 1943, Vọ. 25, p. 48, 1947.

(2) T. Nagata and others: Bull. Earthg. Res. Inst. Vol. 24, p. 221, 1946.

(3) H. Hatakeyana: Journ. Net. Soc. Japan. Vol. 27, p. 372, 1949.

(4) The same electrometer which was used by the authors in the observation of the atuospheric potential gradient on the summit of Mt. Fuji. H. Hatakeyama and T. Uchikawa: Journ. Met. Soc. Japan, Vol. 29, p. 28, 1951. 


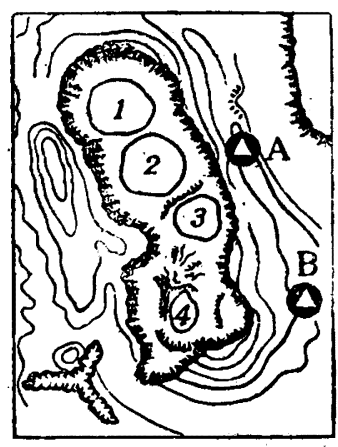

Fig. 1

carried east-southeastwards by the winter moisoon ind the ashes fell down from it. Between the eruption of lava and black smoke only the white smoke flowed out of the crater

\section{Method of Observation}

The observing spot $\mathrm{A}$ is situated to the east-southeast side of the active crater and almost always the eruptionsmoke flowed overhesd of A. Soon after the eruption of black smoke, ashes fell around A. These ashes were very moist. (1) As the observing spot B is situated to the southeast side of the active-crater, generally it was not covered by the eruption-smoke but when the wind-ditection turned to the north-west it was covered by the smoke, and ashes fell around it.

The distance between the center of the crater No. 1 and $A$ is about $400 \mathrm{~m}$, and that between the brim of the crater and $A$ is only $50 \mathrm{~m}$, and the height of $A$ from the sea level is about $1260 \mathrm{~m}$. The distance of $B$ from the center of the crater No. 1 is about $900 \mathrm{~m}$ and the height from the sea level is about the same as that of A. The vertical projection of the crater and the observing spots are shown in Fig. 2. In which the top of the smoke is estimated to be about $150 \mathrm{~m}$ from the brim of the crater, and to be $200 \mathrm{~m}$ or more at $\mathrm{B}$.

Examples of observed values at $A$ and $B$ are tabulated in Table 1 and 2 . In the column 2 of the ta-

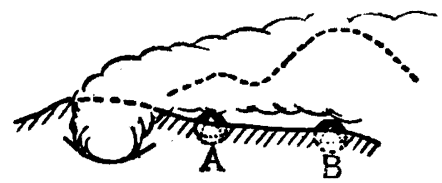

Fig. 2 bles the values of electric potential observed by the electrometer are shown. In the column 3 of the tables, those were reduced to the values of the potential gradient observed on the plane surface. But in the present case the earth's surface is not a plane and the electrometer is situated in a small valley. For this we must apply another reduction. The reduction factors were estimated from the position of the electrometer and the topography around the electrometer considering the equipotential surface. In the column 4 of the tables the values of potential gradient when the spots were virtually plane are tabulated.

In the column 5 of the tables the values of the density of space charge in the smoke estimated by using the values of the potential gradient in the column 4 are shown. The values of the density of space charge in the smoke are calculated by the following formula,

$$
E=4 \pi \rho h \text {, }
$$

assuming that the smoke covered the earth's surface. In the formula, $E$ is the potential gradient, $\rho$ the density of space charge, $h$ the thickness of the smoke layer which is assumed to be $200 \mathrm{~m}$ in Table 1 and to be $250 \mathrm{~m}$ in Table 2 .

On inspecting Table 2, we find a course of electric effect due to an eruption

(1) Dr. Y.Miyake considered its origin as due to the deliguescent constituent such as $\mathrm{MgCl}_{2}$ contained in the outer side film of the ash granule. Y. Migake: Journ. Met. Soc. Japan. Vol. 16, p. $89,1938$. 
Table 1. The variation of the atinospheric potential gradient at $\mathbf{A}$ (at about $12 \mathrm{~h}$, Feb. $17 \mathrm{th}, 1950$ ).

\begin{tabular}{|c|c|c|c|c|c|}
\hline \multirow{2}{*}{$\frac{\text { Line }}{1}$} & \multirow{2}{*}{$\frac{\begin{array}{c}\text { Potential } \\
(\mathrm{V})\end{array}}{23}$} & \multicolumn{2}{|c|}{$\begin{array}{c}\text { Potential gradient } \\
\left(\mathrm{V}^{\top} / \mathrm{m} n\right)\end{array}$} & $\begin{array}{c}\begin{array}{c}\text { Space charge } \\
\text { density } \\
\left(\mathrm{esu} / \mathrm{m}^{3}\right)\end{array} \\
\end{array}$ & Reinarks \\
\hline & & 230 & 9200 & & Covered by the white sinoke but no ash-fall. \\
\hline 2 & 36 & 360 & $\mathrm{~J} 4400$ & 1.9 & Ash-fall. \\
\hline 3 & 23 & 230 & 9200 & & Rather strong ash-fall. \\
\hline 4 & 14 & 140 & 5600 & . & Ash fall in the neighbourhood. \\
\hline 5 & 32 & 320 & 12800 & 1.7 & Covered by the white sinoke, no ash-fall. \\
\hline 6 & 45 & 450 & 18000 & 2.4 & $\begin{array}{l}\text { Towering up of the black sinoke, the strong- } \\
\text { est eruption during the observation. }\end{array}$ \\
\hline 7 & $>220$ & $>2200$ & $>88000$ & $>11.7$ & Strong ash-fall begins. \\
\hline 8 & 0 & 0 & 0 & & Ash-fall ceases. \\
\hline 9 & 19 & 190 & 7600 & & No ash-fall. \\
\hline
\end{tabular}

Table 2. The variation of the atmospheric potential gradient at $\mathbf{B}$ (at about 1lh, Feb. $17 \mathrm{th}, 1950$ ).

\begin{tabular}{|c|c|c|c|c|c|}
\hline \multirow{2}{*}{$\frac{\text { Line }}{1}$} & \multirow{2}{*}{$\frac{\begin{array}{c}\text { Potential } \\
(\mathrm{V})\end{array}}{23}$} & \multicolumn{2}{|c|}{$\begin{array}{c}\text { Potential gradient } \\
(\mathrm{V} / \mathrm{m})\end{array}$} & $\begin{array}{c}\text { Space charge } \\
\text { density } \\
\left(\mathrm{esu} / \mathrm{m}^{3}\right)\end{array}$ & \multirow{2}{*}{ Rernarks } \\
\hline & & 85 & 1280 & & \\
\hline 2 & 25 & 93 & 1400 & & White smoke comes near. \\
\hline 3 & 25 & 93 & 1400 & & White smoke goes away. \\
\hline 4 & 27 & 300 & 1500 & & Black smoke rises high up. \\
\hline 5 & -78 & -288 & -4310 & -0.46 & The tip of black smoke comes to the zenith. \\
\hline 6 & 23 & 85 & 1280 & & Ash-fall begins. \\
\hline 7 & 102 & 377 & 5650 & 0.60 & Ash-fall continues. \\
\hline 8 & 91 & 337 & 5040 & 0.54 & ditto. \\
\hline 9 & 98 & 362 & 5420 & 0.58 & Ash falls in the neighbourhood. \\
\hline 10 & 91 & 337 & 5040 & 0.54 & Ash-fall continues. \\
\hline 11 & 23 & 85 & 1280 & & White smoke flows eastward. \\
\hline 12 & 36 & 133 & 2000 & & Margin of the white snoke is at the zenith. \\
\hline 13 & 48 & 178 & 2670 & & ditto. \\
\hline 14 & 32 & 118 & 1770 & & White smoke rises high up. \\
\hline
\end{tabular}

activity from the line 4 to 11 . It must be remarked that when the tip of the eruption-smoke reached the zenith of the observing spot the potential gradient suddenly changes its sign from positive to negative. And afterwards when the ash begins to fall the potential gradient recovers gradually its positive value and at last it takes a large positve value which is numerically greater than the former positive value.

In Table 1 we find a course of electric effect due to an eruption activity from the line 6 to 9 . Very near the crater as in A, immediately after the towering up of the eruption-smoke the strong ash-fall begins. The electric potential gradient 
takes a very large positive value soon after the rising of the black smoke. And when the ash-fall ceases it recovers gradually to several thousand volts per meter which should be considered to be the normal value at $A$.

Can we explain these two different courses of electric effect by a common distribution of electric charge in the eruption-smoke? We propose a hypothetical

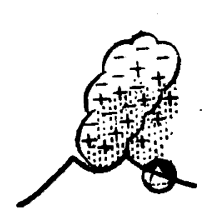

Fig. 3 a

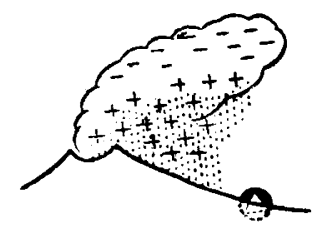

Fig. $3 \mathrm{~b}$ distribution as shown graphically in Fig. 3 a and $b .{ }^{(1)}$ It is only assumed that smaller ash granules have the negative electric charge and larger ash grains have the positive charge. As shown in Fig. $3 \mathrm{~b}$, the electric charges of negative sign are in the upper part of the eruption-

smoke owing to their smaller falling velocity, and the positive charges are in the lower part owing to their greater velocity. But very near the crater, as shown in Fig. $3 \mathrm{a}$, the screening of the electric charge is not yet performed and only the effect of the larger falling ashes which have the positive electric charge is observed.

\section{Experiments on the Electrification of Volcanic Ashes}

The only assumption in the former article was that the smaller ash granules had the negative charge and the larger ones the positive. It is considered that in the eruption-smoke there are many chances in which ash granules collide with each other. It is very influential for our hypothesis that the smaller ash granules get the negative electric charge and the larger get the positive charge in these chances of collision. Following experients were undertaken to test these possibilities.

(a) Experiments with the volcanic ashes of Aso. The same apparatus, which was formerly used by K. Uchikawa, (2) one of the present authors, to investigate the electrification of soil and sands, was used for our experiments.

The brief diagram of the equipment is shown graphically in Fig. 4. In the figure, $A$ is a dish made of copper, having a diameter of $10 \mathrm{~cm}$, and is connected to an electrometer $B$ and is electrically shielded by $C$. The whole electric capacity of the system is $22 \mathrm{~cm}$. D is a thin tinplate which capable of changing the inclination. Previously the layer of ashes of larger grains is pasted over the plate D. Volcanic ashes to be tested are placed on the plate $D$. When it is inclined slightly the ash grains of larger size run down onto the dish $A$ after rubbing with the smaller granules. When inclination is increased, the smaller ash granules run down after rubbing with the larger grains pasted on the plate.

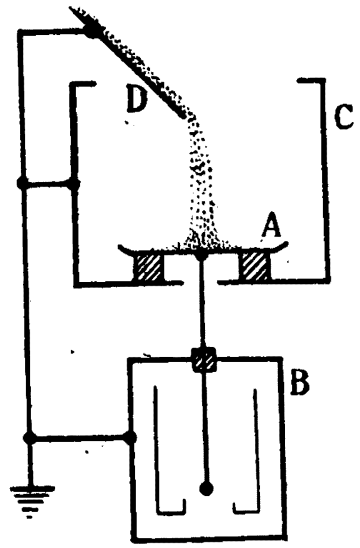

Fig. 4

(1) This distribution of electric charge is contrary to that of the eruption-sinoke of Volcano Asaına. H. Hatakeyaina : Journ. Met. Soc. Japan, Vol. 25, p. 48, 1947.

(2) K. Uchikawa: Journ. Met. Soc. Japan. Vol. 27, p. 288, 1949. 
We made these experiments with the volcanic ashes biought from the neighbourhood of the observing spot A. The average diameter of larger grains is 0.3 $\mathrm{mm}$ and that of smaller granules is $0.04 \mathrm{~mm}$. (1) The deflection of the image of the electrometer is mostly positive when the larger grains are running down and it is negative without exception when the smaller granules are running down.

The averaged value of electric quantity per unit mass for larger ash grains is $+0.004 \mathrm{esu} / \mathrm{g}$ (average of nineteen examples). And that for smaller ash granules is $-0.108 \mathrm{esu} / \mathrm{g}$ (average of nineteen examples also). From these results we may conclude that, when the ashes collide with each other, the larger grains get the positive electricity and the smaller get the ntgative.

These are results of laboratory experiments. But it is very probable that in the eruption-smoke the same process takes place. The hypothetical assumption in the former article is now supported by the experimental evidence.

(b) Experiments with the volcanic ashes of Asama. The disturbance in the atmospheric electric potential gradient caused by the eruption-smoke of Volcano Asama was always negative. But in the neighbourhood of the Volcano when the tip of the eruption-smoke reached the zenith the positive disturbance was often observed. And the hypothesis ${ }^{(2)}$ was proposed that smaller ash granules or atmospheric ions had the positive electric charge and the larger ash grains had the negative. The cause of the separation of electric charge was hypothetically considered that it would be due to the mutual collision.

The simillar experiments as with the volcanic ashes of Aso were undertaken with the volcanic ashes of Asama which were collected in the neighbourhood of the crater by Mr. H. Dobashi, Chief of Karuisawa Meteorological Station. In the case of volcanic ahes of Asama, there are very fine particles. The average size of larger ash grain is about $1.3 \mathrm{~mm}$, that of smaller ash granule is about $0.03 \mathrm{~mm}$ and that of very fine ash particles is about 1.6 microns.

On the contrary to the case of the volcanic ash of Aso, the sign of electricity obtained by the electrometer when the larger ash grains of Asama are running down onto the dish is always negative without exception. The averaged value of electric quantity per unit mass for larger grains is $-0.027 \mathrm{esu} / \mathrm{g}$ (average of ten examples). The hypothetical assumption in the former paper has now obtained the experimental evidence.

The problem why the larger ash grains of Aso get the positive electricity and those of Asama get the negative after the collision with smaller granules was left untouched for the future study.

(1) The group distribution in the size of volcanic ashes of Aso and Asama was already observed by the late Prof. T. Terada and Dr. Y.Miyake. T. Terada: Bull. Earthq. Res. Inst. Vol. 13, p. 801, 1935 ; Y. Miyake: Journ. Met. Soc. Japan. Vol. 16, p. 89, 1938.

(2) H. Hatakeyama: Journ. Met. Soc. Japan. Vol. 25, p. 48, 1947. 